\title{
Intercellular Adhesion Molecule-1 and CD36 Synergize to Mediate Adherence of Plasmodium falciparum-infected Erythrocytes to Cultured Human Microvascular Endothelial Cells
}

\author{
Christopher J. McCormick, ${ }^{\star}$ Alister Craig, ${ }^{\ddagger}$ David Roberts, ${ }^{\ddagger}$ Christopher I. Newbold, ${ }^{\ddagger}$ and Anthony R. Berendt ${ }^{\star}$ \\ $*$ Adhesion and Infection Laboratory, Nuffield Department of Medicine, John Radcliffe Hospital, Headington, Oxford OX3 9DU, United \\ Kingdom; and ${ }^{\ddagger}$ Molecular Parasitology Group, Institute of Molecular Medicine, John Radcliffe Hospital, Headington, Oxford, OX3 9DU, \\ United Kingdom
}

\begin{abstract}
We have compared the adhesion of Plasmodium falciparum-infected erythrocytes to human dermal microvascular endothelial cells (HDMEC) and human umbilical vein endothelial cells (HUVEC) and have assessed the relative roles of the receptors CD36 and intercellular adhesion molecule-1 (ICAM-1). HUVEC (a cell line that expresses high levels of ICAM-1 but no CD36) mediate low levels of adhesion, whereas HDMEC (which constitutively express CD36) mediate high levels of adhesion even before ICAM-1 induction. ICAM-1 expression leads to yet greater levels of adhesion, which are inhibited both by anti-ICAM-1 and CD36 mAbs, despite no increase in the expression of CD36. The results indicate the presence of a substantial population of infected cells that require the presence of both receptors to establish adhesion. Synergy between these receptors could be demonstrated using a number of parasite lines, but it could not be predicted from the binding of these same parasite lines to purified ICAM-1 and CD36. This phenomenon could not be reproduced using either purified receptors presented on plastic, or formalin-fixed HDMEC, suggesting that receptor mobility is important. This is the first study to demonstrate receptor synergy in malaria cytoadherence to human endothelial cells, a phenomenon necessary for parasite survival and associated with disease severity. (J. Clin. Invest. 1997. 100:2521-2529.) Key words: malaria • cytoadherence - intercellular adhesion molecule-1 - receptor • pathogenesis
\end{abstract}

\section{Introduction}

The adhesion of erythrocytes infected with the human malarial parasite, Plasmodium falciparum, to postcapillary venular endothelium is believed to be a major virulence factor $(1,2)$. Adherence is due to specific interactions between high molecular

Address correspondence to Dr. A. Berendt, Adhesion and Infection Laboratory, Nuffield Department of Medicine, Level 7, John Radcliffe Hospital, Headington, Oxford OX3 9DU, United Kingdom. Phone: 44-1865-220279; FAX: 44-1865-220984; E-mail: tony.berendt@ndm. ox.ac.uk Christopher J. McCormick's current address is Department of Biology, University of Leeds, Leeds LS2 9JT, United Kingdom.

Received for publication 24 April 1997 and accepted in revised form 18 September 1997.

J. Clin. Invest.

(C) The American Society for Clinical Investigation, Inc. 0021-9738/97/11/2521/09 \$2.00

Volume 100, Number 10, November 1997, 2521-2529

http://www.jci.org weight parasite-derived adhesins, located at the erythrocyte membrane, termed PfEMP-1 and encoded by the var gene family (3-5), with endothelial molecules that are subverted as receptors. Several host molecules have been shown to be used in this way, including thrombospondin (6), CD36 (7-9), intercellular adhesion molecule-1 (ICAM-1 $)^{1}(10)$, vascular cell adhesion molecule-1 (VCAM-1) (11), E-selectin (11), and chondroitin-4-sulfate (12).

Evidence from postmortem studies links the organ specific sequestration of $P$. falciparum to some forms of clinical disease $(1,2)$. Given that the microvasculature is heterogeneous between different vascular beds (13), and expression of several, if not all, the known receptors is modulated by local environmental factors such as inflammatory cytokines (14-16), it is likely that disease status depends on both the parasite binding phenotype and the expression of receptors in the critical vascular beds. Recently, we have demonstrated that infected erythrocytes (IEs) colocalize with endothelial ICAM-1 expression (and to a lesser extent with CD36 and E-selectin) in the cerebral microvasculature of fatal cases of cerebral malaria (17). Furthermore, in a study of IE sequestration in the placenta, it has been shown recently that erythrocytes taken directly from the placenta have a specific tropism for the adhesion receptor chondroitin-4-sulfate, whereas those from the peripheral blood have additional specificities (18). This may in part explain the failure of several other studies to demonstrate a relationship between endothelial receptor use and disease severity by examining clinical isolates cultured from peripheral blood (19-22).

Individual IEs can bind to more than one receptor (11). The importance of multiple receptor interactions has been demonstrated previously in other vascular intercellular adhesive events. For example, three distinct types of molecular interactions are involved in neutrophil-endothelial adhesion (23). Initial selectin-carbohydrate interactions mediate efficient capture of neutrophils from flow, allowing rolling along the blood vessel. Neutrophil activation by chemokines leads to high avidity interactions between the ICAM family of receptors and $\beta 2$ integrins which can immobilize cells already slowed down by prior rolling but are unable to capture neutrophils directly from flow. An interesting parallel exists between $P$. falciparum and leukocyte adhesion in that ICAM-1 and CD36, respectively, mediate rolling and static adhesion of IEs (24). For these reasons, we were particularly interested in examining the effect of multiple endothelial receptor recognition on IE adherence.

1. Abbreviations used in this paper: HDMEC, human dermal microvascular endothelial cells; HUVEC, human umbilical vein endothelial cells; ICAM-1, intercellular adhesion molecule-1; IE, infected erythrocyte; VCAM-1, vascular cell adhesion molecule-1. 
Previous models used to study IE adhesion in vitro include purified protein immobilized on plastic $(6,7,8,11)$, cDNAtransfected COS and CHO cells $(9,10)$, amelanotic melanoma cells $(7,8,25,26)$, and human umbilical endothelial cells (HUVEC) $(10,27)$. None of these systems meets the requirement for all the appropriate receptors to be expressed in a physiologically relevant and coordinately regulated fashion. Human dermal microvascular endothelial cells (HDMEC) express both CD36 (28) and ICAM-1 (29), the latter being modulated by cytokines such as TNF. A study of the adhesion of two parasite lines to HDMEC demonstrated that both ICAM-1 and CD36 were capable of mediating significant adhesion but did not draw conclusions about their relative importance in sequestration (30). Therefore, we isolated and characterized HDMEC, and performed adhesion assays to HDMEC and HUVEC with five different well-defined laboratory-adapted parasite lines. Using $\mathrm{mAbs}$ to block different receptor interactions, we examined the relative roles of ICAM-1 and CD36 and found that when coexpressed on intact endothelial cells, these two receptors operate synergistically to mediate high levels of cytoadherence.

\section{Methods}

Materials. All chemicals were from Sigma Chemical Co. (Dorset, UK), unless otherwise indicated; culture media (PBS, HBSS, M199, RPMI 1640) and supplements (penicillin/streptomycin, gentamicin, FBS, Hepes) were from Gibco Laboratories (Middlesex, UK); and Falcon tissue culture plasticware were from Becton Dickinson (Oxfordshire, UK).

$m A b s$. Anti-ICAM-1 mAbs used were 15.2 (IgG1) (a gift from Dr. N. Hogg) and RR1.1 (IgG1) (a gift from Dr. R. Rothlein, Boehringer Ingelheim, Ridgefield, UK). Dr. J. MacGregor provided the anti-CD36 mAbs 10/5 and 13/10 (both IgG2a) while 8A6, an antiCD36 IgG1 mAb, was a gift from Dr. J. Barnwell. Dr. D. Haskard provided the anti-E-selectin $\mathrm{mAb}, 1.2 \mathrm{~B} 6$ (IgG1), and the antiVCAM-1 mAb, 1.4C3 (IgG1). Control mAbs were 28.14.8S, an IgG2a that recognizes mouse MHC I (a gift from Dr. A. Townsend, IMM, Oxford, UK), 44, an IgG1 that recognizes CD11b (a gift from Dr. N. Hogg), and anti-Plasmodium chabaudi p195 antigen mAbs No. 1 (IgG2a) and No. 3 (IgG1).

Proteins. ICAM-1-Fc was a dimerized chimeric molecule consisting of the five extracellular domains of ICAM-1 linked at the carboxy terminus to the hinge region and the third and fourth domain of the human IgG2a heavy chain. Purified CD36 was obtained from human platelets using a previously described method (31).

Endothelial isolation and culture. HUVEC were obtained using an adaptation to a previously published method (32). Umbilical cords were collected in M199 medium containing $50 \mathrm{U} / \mathrm{ml}$ penicillin, $50 \mathrm{mg} /$ $\mathrm{ml}$ streptomycin and stored at $4^{\circ} \mathrm{C}$ for up to $24 \mathrm{~h}$ before use. Each end of the cord was cannulated with a Portex luerlock adaptor (Southern Syringe Ltd., London, UK) and the adaptor was secured by tying fishing line around the cord at the locations of these adaptors. The vein was perfused with PBS to remove residual blood contents and the entire vessel lumen was filled with M199 supplemented with $50 \mathrm{U} / \mathrm{ml}$ penicillin, $50 \mathrm{mg} / \mathrm{ml}$ streptomycin, and $0.5 \mathrm{mg} / \mathrm{ml}$ collagenase type IA. After a 20 -min incubation at $37^{\circ} \mathrm{C}$, a combination of squeezing and rubbing the length of the cord between finger and thumb was used to dislodge loosened endothelial cells. The resulting endothelial cell suspension was collected, pelleted by centrifugation, resuspended in growth medium (M199 medium supplemented with $50 \mathrm{U} / \mathrm{ml}$ penicillin, $50 \mathrm{mg} / \mathrm{ml}$ streptomycin, $90 \mu \mathrm{g} / \mathrm{ml}$ heparin, $5 \mathrm{ng} / \mathrm{ml}$ recombinant basic fibroblast growth factor, and $20 \%$ FBS), and allowed to attach to a gelatin-coated $25-\mathrm{cm}^{2}$ tissue culture flask. Cells were fed every $2 \mathrm{~d}$ and grown for up to three passages.
HDMEC were obtained from human foreskin tissue using an adaptation to previously published methods (33-35). Human foreskin tissue was obtained with local ethical committee approval from elective circumcisions performed at the John Radcliffe Hospital and stored in M199 medium containing $400 \mathrm{U} / \mathrm{ml}$ penicillin, $200 \mathrm{mg} / \mathrm{ml}$ streptomycin at $4^{\circ} \mathrm{C}$ for up to $24 \mathrm{~h}$ before use. Foreskins were washed in HBSS, dissected into $2-3-\mathrm{mm}^{2}$ sections and incubated at $4^{\circ} \mathrm{C}$ overnight in M199 medium containing $400 \mathrm{U} / \mathrm{ml}$ penicillin, $200 \mathrm{mg} / \mathrm{ml}$ streptomycin, and $1 \mathrm{mg} / \mathrm{ml}$ collagenase type $1 \mathrm{~A}$. Tissue segments were washed three times in HBSS and the microvessels were released by compression of the tissue segments using a sterile spatula. To remove large debris, vessel preparations were passed through a $100-\mu \mathrm{m}$ nylon mesh (Lockertex, Warrington, UK). The effluents were collected, pelleted by centrifugation at $200 \mathrm{~g}$ for $10 \mathrm{~min}$, and the resulting cell pellets were resuspended in growth medium (M199 medium supplemented with $50 \mathrm{U} / \mathrm{ml}$ penicillin, $50 \mathrm{mg} / \mathrm{ml}$ streptomycin, $90 \mu \mathrm{g} / \mathrm{ml}$ heparin, $10 \mathrm{ng} / \mathrm{ml}$ recombinant epidermal growth factor, $3.3 \times 10^{-4} \mathrm{M}$ 3 -isobutyl-1-methylxanthine, and $30 \%$ pooled human serum; Regional Blood Transfusion Services, Oxford, UK) and allowed to attach to a gelatin-coated $25-\mathrm{cm}^{2}$ flask. Cells were fed every $2 \mathrm{~d}$ and passaged up to six times before freezing in $90 \%$ FBS, $10 \%$ dimethylsulfoxide. On thawing, the cells were shown to maintain a differentiated state for more than three passages and to express constitutive endothelial markers CD31, von Willebrand factor, ICAM-2, and Ulex europa lectin-specific carbohydrates. The cells also expressed activation-dependent endothelial characteristic markers VCAM-1 and E-selectin after exposure to TNF (Genzyme Diagnostics, Kent, UK).

Parasite culture. A4, $\mathrm{C} 18$, and $\mathrm{C} 28$ are parasite clones originating from the Brazilian IT4/25/5 line (36). The ITG-ICAM parasite line is also derived from IT4/25/5 but was generated by repeated selection for binding to ICAM-1 (21) and was a gift from Dr. C. Ockenhouse. FCR3A2 is a parasite clone originating from the African FCR-3 line and was provided by Dr. K. Marsh. Parasites were cultured in human group O erythrocytes using RPMI 1640 medium supplemented with $2 \mathrm{mM}$ L-glutamine, $37.5 \mathrm{mM}$ Hepes, $10 \mathrm{mM}$ glucose, $25 \mu \mathrm{g} / \mathrm{ml}$ gentamicin, and $10 \%$ human serum, with the $\mathrm{pH}$ adjusted to 7.2 using $\mathrm{NaOH}$, and under a gas mixture of $96 \%$ nitrogen, $3 \%$ carbon dioxide, and $1 \%$ oxygen (37). Parasites were synchronized twice a week by either sorbitol lysis or gelatin floatation and used for experiments during the later half of their intraerythrocytic life cycle.

Adhesion assays. Adhesion to endothelium was studied using a modified version of a previously described method (10). Endothelium grown to confluence on 13-mm Thermanox coverslips was washed and incubated in binding medium (RPMI 1640 medium without $\mathrm{HCO}_{3}{ }^{-}, 10 \mathrm{mM}$ glucose, $25 \mathrm{mM}$ Hepes, 1\% BSA, 0.05\% $\mathrm{NaN}_{3}$ ). Where specific receptor blocking was required, the binding medium was also supplemented with saturating concentrations $(2 \mu \mathrm{g} / \mathrm{ml})$ of anti-ICAM-1 and/or anti-CD36 adhesion blocking mAbs. After 30 min the coverslips were transferred to new 24-well plates containing fresh binding medium via a series of two dip washes and a $250-\mu \mathrm{l}$ volume of a $2 \%$ hematocrit, $3-10 \%$ parasitemia suspension was introduced into each well. IE were incubated with the endothelial monolayers for a 60 -min incubation at $37^{\circ} \mathrm{C}$, during which time the red cells were resuspended every $10 \mathrm{~min}$. Unbound erythrocytes were removed by a 1-h gravity wash and the remaining bound cells were fixed for a minimum of $1 \mathrm{~h}$ in protein-free binding medium supplemented with $2 \%$ glutaraldehyde. Cells were stained with $5 \%$ Giemsa for $20 \mathrm{~min}$, dried, mounted on slides using DPX mountant (BDH Laboratory Supplies, Leicester, UK), and the levels of binding were assessed microscopically.

IE adherence to purified proteins was examined using a modified version of an established method. Receptor solutions were placed as $2-\mu l$ spots on to the surface of Falcon $60 \times 15 \mathrm{~mm}$ bacteriological plastic petri dishes (Falcon 1007; Becton Dickinson). Dishes were placed in a moist box for $1 \mathrm{~h}$ at $37^{\circ} \mathrm{C}$ to allow the receptors to adsorb to the plastic surface. The receptor solutions were aspirated off and the remaining sites on the plastic were blocked with Tris-buffered saline supplemented with $1 \%$ BSA for $2 \mathrm{~h}$ at $37^{\circ} \mathrm{C}$ (or overnight at $4^{\circ} \mathrm{C}$ ). 
The procedure was similar on occasions where receptor densities were to be determined, except that $4-\mu l$ drops of receptor solution were adsorbed to the petri dishes and duplicate spots were also adsorbed to bacteriological plastic 96-well plates. Afterwards, the blocking solution was removed by aspiration and the dishes were washed twice with binding medium before introducing $1.25 \mathrm{ml}$ of a parasite suspension at 2\% hematocrit and 3\% parasitemia to each dish. Binding was allowed to occur over $1 \mathrm{~h}$ at $37^{\circ} \mathrm{C}$ with resuspension of red cells every $10 \mathrm{~min}$. Unbound erythrocytes were removed by three to five washes with $1.5 \mathrm{ml}$ of binding medium and a final wash with $1.5 \mathrm{ml}$ of protein-free binding medium. The dishes were then fixed with $1 \%$ glutaraldehyde in protein-free binding medium, stained with $5 \%$ Giemsa for $20 \mathrm{~min}$, and the levels of adhesion were assessed microscopically.

Detection of endothelial antigens by ELISA. A 96-well format was used to detect surface expression of antigens. The primary mAbs were diluted in wash buffer (PBS $+2 \%$ [vol/vol] heat-inactivated FBS, supplemented with $0.05 \%$ [wt/vol] $\mathrm{NaN}_{3}$ ), $50 \mu \mathrm{l}$ of which was added to each well and the plates left on ice. After $30 \mathrm{~min}$, the antibody solution was removed by washing and $50 \mu$ of wash buffer, containing a 1:1,000 dilution of an alkaline phosphatase-conjugated goat anti-mouse immunoglobulin, was added to each well. The plates were left on ice for $60 \mathrm{~min}$ before unbound antibody was removed by a further series of washes. A 200- $\mu$ l solution of Sigma FAST buffer $(1 \mathrm{mg} / \mathrm{ml} p$-nitrophenyl phosphate, $0.2 \mathrm{M}$ Tris buffer, $\mathrm{pH}>8.0$ in $\mathrm{ddH}_{2} \mathrm{O}$ ) was added to each well and the plates were left in the dark at room temperature for up to $1 \mathrm{~h}$. Color development was terminated by the addition of a further $50 \mu \mathrm{l}$ of $3 \mathrm{M} \mathrm{NaOH}$ to each well and the absorbance at $405 \mathrm{~nm}$ was determined using a microtiter plate reader.

Radioimmunoassay. Antibodies (15.2, 10/5, 28.14.8S, 44) were radiolabeled with ${ }^{125} \mathrm{I}$ using Iodogen (1,3,4,6-tetrachloro-3,6-diphenylglycoluril) (Pearce Chemicals, Chester, UK) according to a previously published technique (38) and unincorporated label was removed using a Sephadex G25 column. Specific activity was calculated from having determined the activity and amount of $\mathrm{mAb}$ present in a given volume using trichloroacetic acid precipitation and SDSPAGE, respectively. Saturated binding of epitopes was shown to occur at $2 \mu \mathrm{g} / \mathrm{ml}$ for both radiolabeled anti-CD36 and anti-ICAM-1 $\mathrm{mAbs}$. Site densities were determined on endothelium grown to confluency on 13-mm Thermanox coverslips and on purified receptors adsorbed to the bottom of Falcon bacteriological plastic 96-well plates as described. Receptor-bearing surfaces were incubated at $4{ }^{\circ} \mathrm{C}$ in binding medium supplemented with $2 \mu \mathrm{g} / \mathrm{ml}$ of iodinated antibody. After $30 \mathrm{~min}$, unbound $\mathrm{mAb}$ was removed by repeated washes in icecold binding medium. Bound antibody was then solubilized using $1 \%$ SDS in PBS and the activity of the solution was determined. Site density was calculated assuming a $1: 1$ ratio of $\mathrm{mAb}$ to antigen after subtracting nonspecific isotype control background.

\section{Results}

Characterization of HDMEC isolates and cytokine responses. HDMEC cell lines formed monolayers, showed contact inhibition, and displayed a distinctive cobblestone morphology that was noticeably altered on cytokine activation. By indirect immunofluorescence, $>90 \%$ of the HDMEC expressed the constitutive endothelial markers CD31 and the carbohydrates recognized by Ulex europa lectin, as well as possessing intracellular Wiebel-Pallade bodies containing von Willebrand factor (data not shown). Approximately $90 \%$ of the cells constitutively expressed CD36. Levels of ICAM-1, E-selectin, and VCAM-1 expression were negligible on unactivated HDMEC, but were increased after activation with TNF or IL-1 $\beta$, as determined both by FACS ${ }^{\circledR}$ and cell-based ELISA (Fig. 1).

Microvascular endothelial cells mediate higher levels of adhesion than umbilical vein endothelium. We compared the ad-

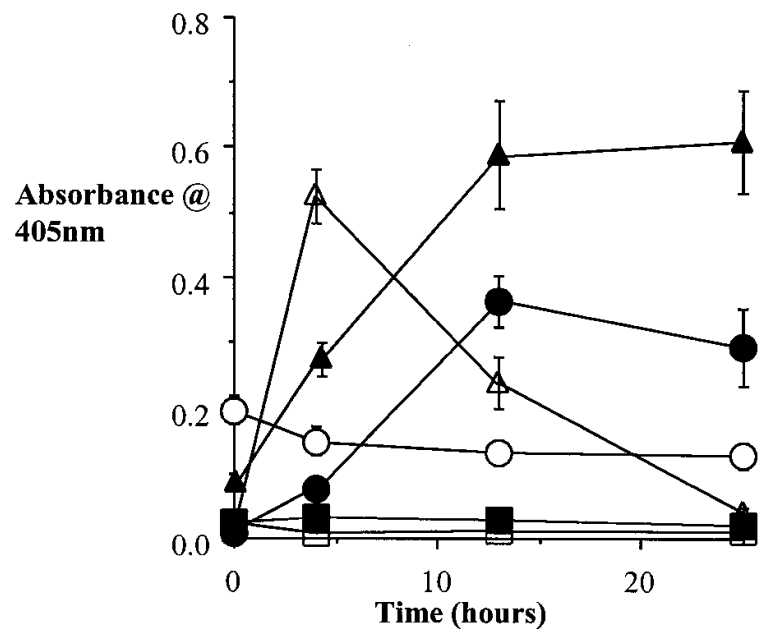

Figure 1. ELISA results showing the relative levels of surface expression of CD36 (open circles), ICAM-1 (closed triangles), VCAM-1 (closed circles), and E-selectin (open triangles) on HDMEC over a 25-h time course, after activation with $100 \mathrm{U} / \mathrm{ml} \mathrm{TNF}$. Irrelevant anti$P$. chabaudi $\mathrm{p} 195 \mathrm{mAbs}$ of isotype IgG1 (closed squares) and $\mathrm{IgG} 2 \mathrm{a}$ (open squares) were included as controls. Values represent the mean \pm SD of one of three experiments.

hesion to HDMEC and HUVEC of a parasite clone, A4, able to bind to both ICAM-1 and CD36 (Fig. 2). Endothelial cells were either used unactivated or after activation with $100 \mathrm{U} / \mathrm{ml}$ TNF for $24 \mathrm{~h}$. Endothelial cells from the two sources showed marked differences in their ability to support IE binding. Adhesion was considerably greater to HDMEC, irrespective of activation status. On resting endothelium, A4 adhesion to HDMEC approached levels nearly 10 -fold higher than that seen to HUVEC. TNF activation caused an increase in IE binding to both endothelial cell lines which was much more pronounced on HDMEC.

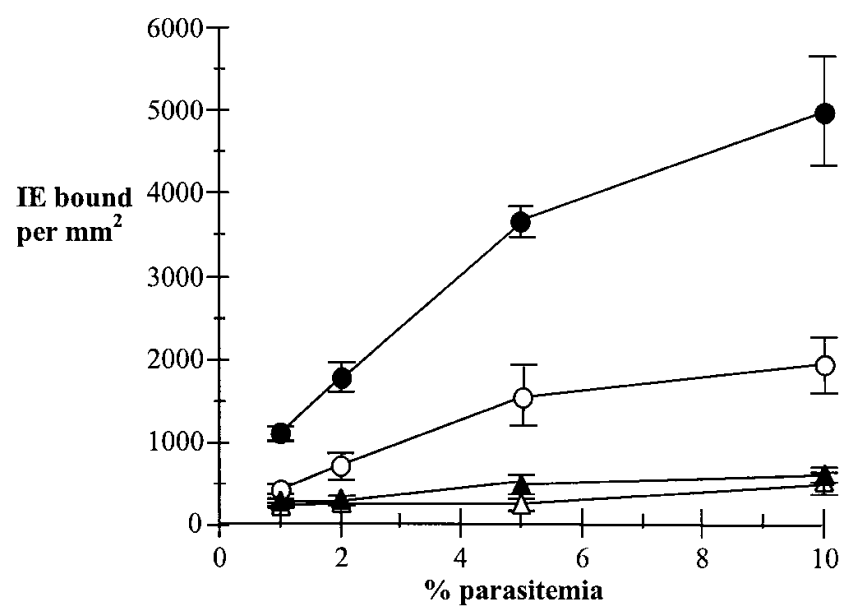

Figure 2. Adhesion of A4 to HDMEC and HUVEC. Binding was assessed over a range of parasitemias to unactivated (open circles) and TNF-activated (closed circles) HDMEC, and compared with unactivated (open triangles) and TNF-activated (closed triangles) HUVEC. The graph shows the mean $\pm \mathrm{SD}$ of a single experiment, the levels of adhesion being representative of those seen on numerous occasions when examining A4 adhesion to either HDMEC or HUVEC. 
Table I. Determination of ICAM-1 and CD36 Site Densities on HDMEC and HUVEC Using [25I]-labeled Antibodies

\begin{tabular}{lcr}
\hline & \multicolumn{2}{c}{ Receptor site densities $\left(\times 10^{6} \mathrm{~mm}^{-2}\right)^{*}$} \\
\cline { 2 - 3 } \multicolumn{1}{c}{ Endothelial cell lines } & \multicolumn{1}{c}{ CD36 } & ICAM-1 \\
\hline Resting HDMEC & $86 \pm 14$ & $6 \pm 3$ \\
24-h TNF-activated HDMEC & $93 \pm 13$ & $159 \pm 32$ \\
Resting HUVEC & Not detected & $61 \pm 19$ \\
24-h TNF-activated HUVEC & Not detected & $964 \pm 56$ \\
\end{tabular}

*Unless indicated otherwise, values represent the mean \pm SE of three separate determinations. ${ }^{\ddagger}$ On one of two occasions when the site density of CD36 on HUVEC was examined, a low but just detectable level of this receptor was found $\left(4.2 \times 10^{6} \mathrm{~mm}^{-2}\right)$.

Levels of adhesion correlate primarily with CD36 expression and only secondarily with ICAM-1 site density. To establish whether differences in adhesion reflected differences in levels of receptor expression, the site densities of ICAM-1 and CD36 were determined for both endothelial cell lines (Table I). On unactivated cells, CD36 was present on HDMEC at a site density of $9 \times 10^{7} \mathrm{~mm}^{-2}$, but was only detectable on one of the two HUVEC isolates examined quantitatively, where it was at a site density 20-fold lower than seen on HDMEC. (On numerous other isolates of HUVEC examined by FACS ${ }^{\circledR}$ or cell-based ELISA, CD36 expression was below the limits of detection.) In contrast, the levels of ICAM-1 expression were 10 -fold higher on HUVEC $\left(6 \times 10^{7} \mathrm{~mm}^{-2}\right)$ than on HDMEC $\left(6 \times 10^{6} \mathrm{~mm}^{-2}\right)$ and so did not correlate with the relative levels of IE binding.

On TNF-activated endothelium, the raised levels of adhesion did not appear to be explicable by changes in CD36 expression since the site density of this receptor remained unaltered on HDMEC and undetectable on HUVEC. The increase in adhesion did coincide with an increase in ICAM-1 expression. However, while the levels of ICAM-1 expression on activated endothelial cells were fivefold higher on HUVEC $(9.6 \times$ $\left.10^{8} \mathrm{~mm}^{-2}\right)$ than on HDMEC $\left(1.6 \times 10^{8} \mathrm{~mm}^{-2}\right)$, the increase in IE adherence was greater for HDMEC.

A4 adhesion to HDMEC depends on both CD36 and ICAM-1. To establish the relative importance of CD36 and ICAM-1, adhesion blocking mAbs to CD36 (mAb 8A6) and ICAM-1 (mAb 15.2) were used to analyze the role of these two receptors in attachment of A4 to HDMEC (Fig. 3).

On resting HDMEC the binding of A4 was markedly inhibited by mAb 8A6, demonstrating that adhesion is almost entirely CD36-dependent. Blocking with mAb 15.2 had no effect on IE adherence, indicating that there is insufficient ICAM-1 to play a role in adhesion to resting HDMEC, consistent with the ELISA and site density data.

On TNF-activated HDMEC, ICAM-1 made a significant contribution to the adherence of A4. The substantial binding increment induced by TNF activation was inhibited in the presence of mAb 15.2 (91\% inhibition of increment), indicating that ICAM-1 is entirely responsible for the enhanced adhesion seen. As the residual level of adhesion in the presence of $\mathrm{mAb} 15.2$ was reduced to a negligible amount if the blocking anti-CD36 mAb 8A6 was also included, it appears that ICAM-1 and CD36 account for virtually all A4 adhesion to activated
HDMEC. These two results also mean that when ICAM-1 is unavailable thorough lack of expression or mAb inhibition, CD36 accounts for the same level of adhesion on activated and unactivated HDMEC. Therefore, it was surprising that the adhesion of A4 to activated HDMEC, which is clearly ICAM-1dependent, was also dramatically reduced in the presence of the CD36 mAb alone. The reduction was more than would be expected if the levels of adhesion supported by CD36 on activated and unactivated HDMEC were the same. This implied the presence of a population of IEs only able to bind when both CD36 and ICAM-1 were available. The alternative explanation that $\mathrm{mAbs}$ cause a nonspecific reduction in adhesion can be ruled out because control mAbs to nonblocking epitopes of ICAM-1 and CD36 had no effect on the adhesion of A4 to either resting or activated HDMEC (data not shown).

Because the presence of a blocking antibody only reduces IE adhesion by selectively preventing engagement of a single receptor type, the level of binding of A4 to HDMEC supported by ICAM-1 and CD36 individually, and that supported by the two receptors together, can be determined. The contribution made by ICAM-1 and CD36 when presented together is the difference between the levels of adhesion to unblocked HDMEC and that seen when both receptors are blocked with antibodies. To estimate the number of IEs able to adhere by one receptor alone, binding is compared between HDMEC when one receptor is blocked and when both are blocked. By taking this approach, the level of adhesion supported by both

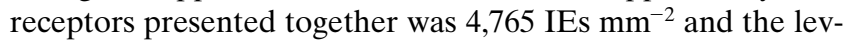
els supported by ICAM-1 or CD36 alone were 524 and 1,951 IEs $\mathrm{mm}^{-2}$, respectively. Thus, it appears that ICAM-1 and CD36 are operating synergistically in enabling A4 adhesion to HDMEC, with $\sim 50 \%$ of the cells adhering to activated HDMEC by using both receptors.

Receptor synergy varies between strains and is not predicted by adhesion to purified proteins. To examine whether synergistic adhesion to both receptors was a unique, rare, or ubiqui-

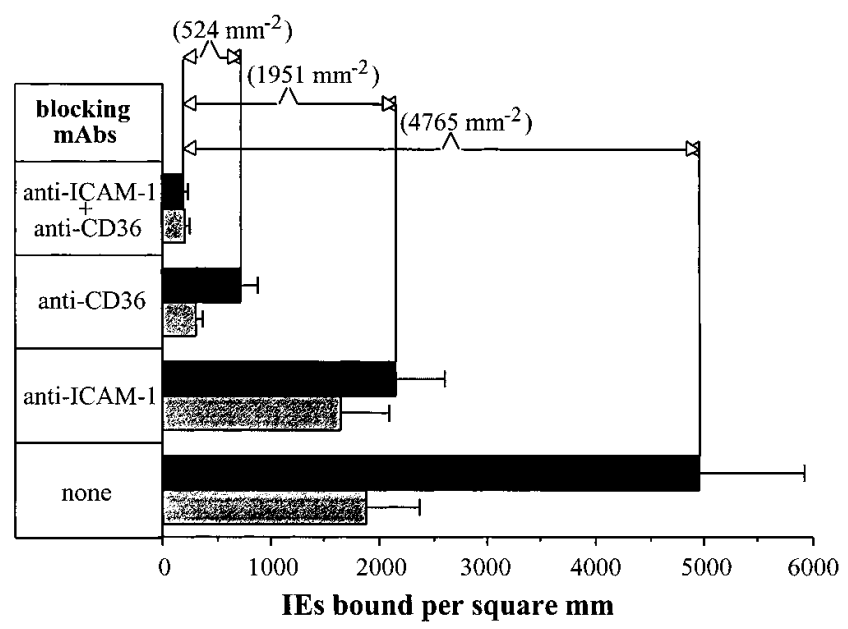

Figure 3. Assessment of the contributions that ICAM-1 and CD36 make to A4 adhesion to HDMEC. Endothelium was either unactivated (gray boxes) or TNF-activated (black boxes). mAbs 15.2 (antiICAM-1) and 8A6 (anti-CD36) were used to block receptor engagement. Values in parentheses represent individual and dual receptor contributions. Results show the mean $\pm \mathrm{SE}$ of five separate experiments. 


\begin{tabular}{lcccccc}
\hline & & \multicolumn{3}{c}{ IEs bound $\left(\mathrm{mm}^{-2}\right)^{*}$} \\
\cline { 3 - 6 } Receptor & Coating conc. & A4 & C18 & C28 & ITG-ICAM \\
\hline ICAM-1-Fc & $10 \mu \mathrm{g} / \mathrm{ml}$ & NB & NB & NB & $605 \pm 275$ & FCR3A2 \\
& $40 \mu \mathrm{g} / \mathrm{ml}$ & $1038 \pm 97$ & $220 \pm 35$ & $165 \pm 44$ & $8085 \pm 578$ & NB \\
CD36 & $15 \mathrm{ng} / \mathrm{ml}$ & $1183 \pm 330$ & $825 \pm 275$ & $3135 \pm 605$ & $1389 \pm 385$ & $2338 \pm 38$ \\
& $30 \mathrm{ng} / \mathrm{ml}$ & $3974 \pm 921$ & $2943 \pm 413$ & $7178 \pm 880$ & $5486 \pm 481$ & $5473 \pm 385$ \\
& & & & & \\
\hline
\end{tabular}

$*$ Values represent the mean $\pm \mathrm{SD}$ for one of two experiments. $N B$, No binding.

tous phenomenon, four other parasite lines were chosen. These lines had been characterized already in terms of high, low, or absent adhesion to purified recombinant ICAM-1-Fc, but less data were available on their adhesion to CD36 and no direct comparisons had been made between all four. Thus, the ability of these lines to adhere to ICAM-1-Fc and CD36 were compared with the A4 parasite clone.

Of the five parasite lines, four showed variable levels of binding to ICAM-1-Fc, while one line, FCR3A2, completely lacked the ability to adhere to this receptor (Table II). ITG-ICAM showed the highest levels of adherence, binding to ICAM-1-Fc at least eightfold more than did A4. The levels of ICAM-1-Fc binding by the parasite lines $\mathrm{C} 28$ and $\mathrm{C} 18$ were similar, being approximately fivefold lower than seen with A4.
IE adhesion to purified CD36 also varied between the five parasite lines (Table II). However, this variation was much less than that seen with adhesion to ICAM-1-Fc, there being at most a two- to threefold difference. Having established the relative binding abilities of the four parasite lines to both ICAM-1 and CD36, their adhesion to HDMEC was examined, again using $\mathrm{mAbs}$ to assess individual receptor contributions (Fig. $4, a-d)$.

All parasite lines showed considerably reduced attachment to unactivated HDMEC in the presence of the anti-CD36 mAb 8A6, while the anti-ICAM-1 mAb 15.2 had no effect on binding. Thus CD36 would appear to be the primary receptor for the attachment of the four lines to resting HDMEC. However, higher background binding of IEs in the presence of

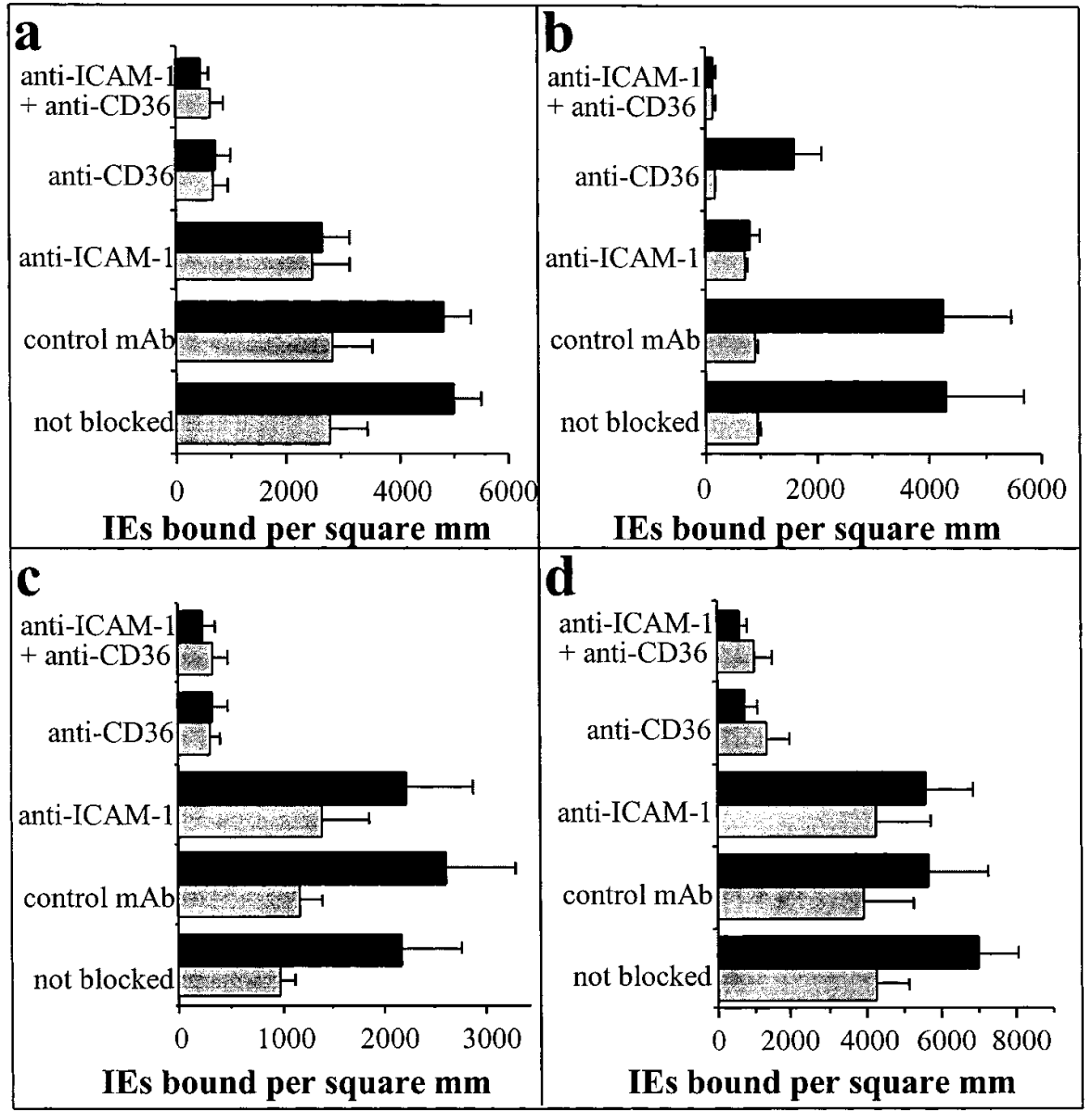

Figure 4. Assessment of receptor contributions for adhesion of various parasite lines to HDMEC. Adhesion of C18 $(a)$, ITG-ICAM $(b)$, C28 (c), and FCR3A2 $(d)$ was examined to unactivated (gray boxes) and TNF-activated (black boxes) HDMEC. mAbs 15.2 (anti-ICAM-1) and 8A6 (antiCD36) were used to block receptor engagement. The nonblocking anti-ICAM-1 mAb, RR1.1, was used as a negative control. Results show the mean \pm SE of three separate experiments for each parasite line. 
Table III. Parasite Adhesion to ICAM-1-Fc and CD36 when Presented Together on a Plastic Surface and Using mAbs to Assess Receptor Contributions

\begin{tabular}{|c|c|c|c|c|c|}
\hline \multirow[b]{2}{*}{ CD36 site density } & \multirow[b]{2}{*}{ ICAM-1 site density } & \multicolumn{4}{|c|}{ IEs bound $\left(\mathrm{mm}^{-2}\right)^{*}$} \\
\hline & & Not blocked & Anti-ICAM-1 & Anti-CD36 & Anti-ICAM-1 + anti-CD36 \\
\hline $5.9 \pm 0.2$ & $23.6 \pm 3.6$ & $4294 \pm 403$ & $2882 \pm 97$ & $2116 \pm 161$ & $95 \pm 11$ \\
\hline $8.2 \pm 0.5$ & $28.1 \pm 3.4$ & $4712 \pm 356$ & $3267 \pm 260$ & $2270 \pm 150$ & $110 \pm 15$ \\
\hline
\end{tabular}

*Values represent the mean \pm SE of three separate experiments. ${ }^{\ddagger}$ Site densities were determined in parallel with adhesion assays and values represent the mean $\left(\times 10^{7} \mathrm{~mm}^{-2}\right) \pm \mathrm{SE}$.

blocking antibodies to both ICAM-1 and CD36 was noticeable with lines FCR3A2, C28, and C18.

On activated HDMEC, the binding of all four lines was elevated above resting levels. As with A4, the enhanced adhesion of ITG-ICAM and C18 was completely inhibited by 15.2 , indicating that increased expression of ICAM-1 was responsible (Fig. 4, $a$ and $b$ ). Using the same criteria discussed previously, the contributions that ICAM-1 and CD36 make to ITG-ICAM and $\mathrm{C} 18$ adhesion to HDMEC can be determined, both for the receptors when presented individually and when presented together. For ITG-ICAM, the calculated sum of the level of binding provided by both receptors as individual entities is 2,142 IEs $\mathrm{mm}^{-2}$, whereas the observed level of adhesion is 4,199 IEs $\mathrm{mm}^{-2}$. For C18 these levels are 2,494 (expected) and 4,549 (observed) IEs $\mathrm{mm}^{-2}$, respectively. Thus ICAM-1 and CD36 interact synergistically in allowing ITG-ICAM and C18 adhesion to HDMEC.

In contrast to ITG-ICAM and C18, the increase in binding of both C28 and FCR3A2 to activated HDMEC was unaffected by the presence of $\mathrm{mAb} 15.2$ (Fig. 4, $c$ and $d$ ), indicating that ICAM-1 is not required for the increase in binding of these parasite lines to HDMEC. This is despite the fact that the adhesion of $\mathrm{C} 28$ and $\mathrm{C} 18$ to ICAM-1-Fc is equivalent. As with the other parasite lines, blocking CD36 on TNF-activated HDMEC with mAb 8A6 substantially reduced the binding of $\mathrm{C} 28$ and FCR3A2. In these instances the levels of binding were similar to those seen on unactivated HDMEC in the presence of the $8 \mathrm{~A} 6 \mathrm{mAb}$.

Presentation of ICAM-1 and CD36 on plastic is insufficient for receptor synergy. We attempted to reproduce synergy between ICAM-1 and CD36 using purified receptors immobilized on plastic. ICAM-1 and CD36 were coadsorbed on to an inert plastic surface at site densities similar to those found on TNF-activated HDMEC. Individual receptor contributions were determined using two alternative strategies. The first was as before, to use mAbs to prevent receptor engagement (Table a

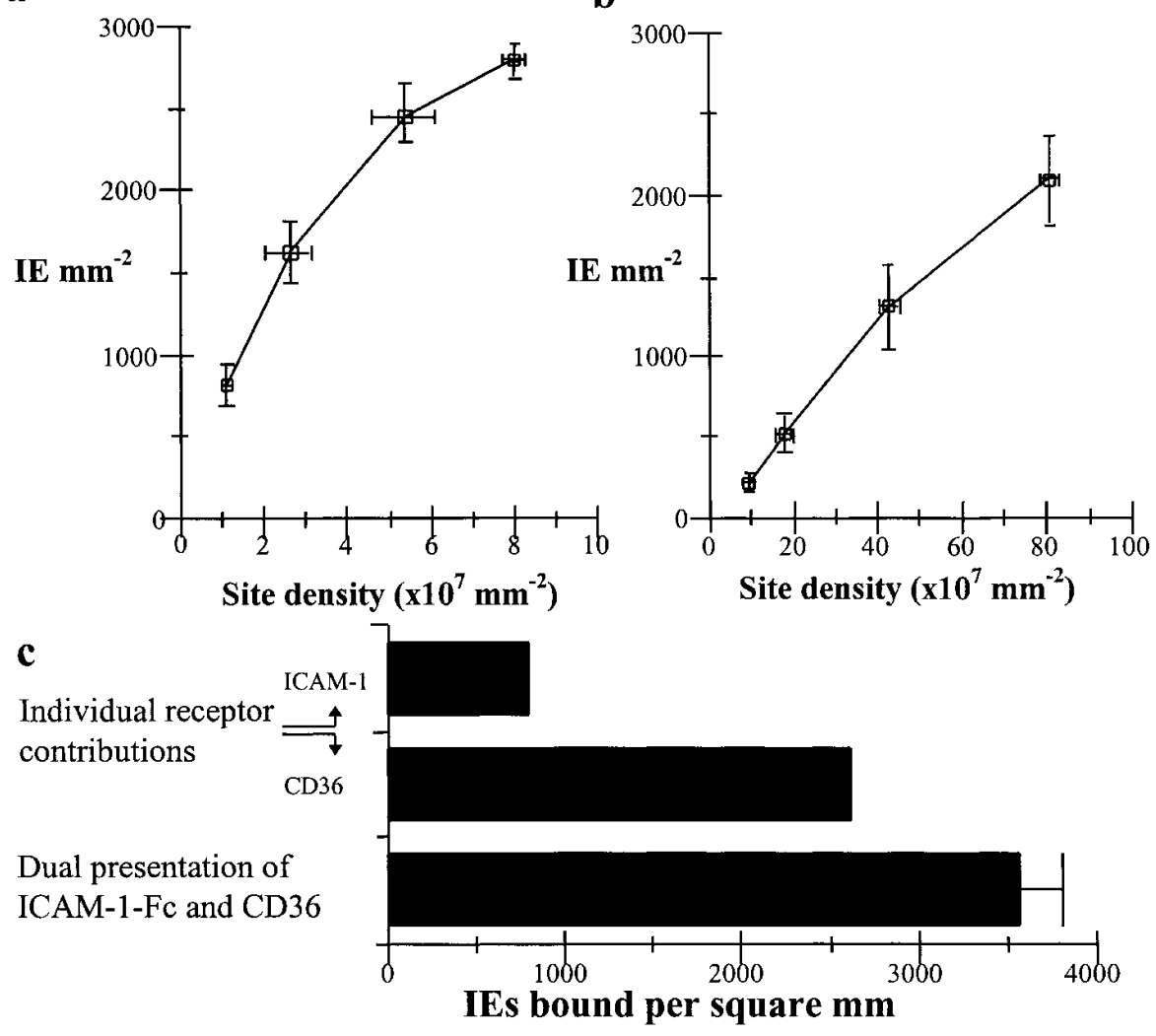

Figure 5. Dual presentation of ICAM-1 and CD36 on plastic only allows for additive receptor contributions to IE adhesion. IE adhesion to a known site density of ICAM-1-Fc and CD36 was compared with the levels of binding supported by the same site densities of receptors when presented individually $(c)$, which in turn were estimated from calibration curves of parasite binding versus CD36 (a) and ICAM-1-Fc (b) site density. Results are from one of two experiments and show the mean \pm SD of four and nine separate determinations for site density and IE adhesion, respectively. 
Table IV. Effect of Fixation and Temperature on the Receptor Dependency of A4 Adhesion to TNF-activated HDMEC

\begin{tabular}{|c|c|c|c|c|c|c|c|}
\hline \multirow[b]{2}{*}{ Temperature } & \multirow[b]{2}{*}{ Fixation $^{\ddagger}$} & \multicolumn{6}{|c|}{ IEs bound $\left(\mathrm{mm}^{-2}\right)^{*}$} \\
\hline & & Not blocked & Anti-ICAM-1 & Anti-CD36 & Anti-ICAM-1 + anti-CD36 & $\begin{array}{l}\text { Sum of individual } \\
\text { receptor contributions }\end{array}$ & $\begin{array}{l}\text { Level of binding supported by } \\
\text { presentation of both receptors }\end{array}$ \\
\hline \multirow[t]{2}{*}{$37^{\circ} \mathrm{C}$} & - & $3437 \pm 339$ & $1610 \pm 342$ & $627 \pm 27$ & $163 \pm 66$ & 1911 & 3274 \\
\hline & + & $1286 \pm 334$ & $988 \pm 370$ & $294 \pm 61$ & $124 \pm 33$ & 1034 & 1162 \\
\hline \multirow[t]{2}{*}{$4^{\circ} \mathrm{C}$} & - & $5468 \pm 589$ & $4008 \pm 459$ & $1281 \pm 282$ & $324 \pm 75$ & 4641 & 5144 \\
\hline & + & $2719 \pm 281$ & $2270 \pm 218$ & $417 \pm 190$ & $147 \pm 31$ & 2393 & 2572 \\
\hline
\end{tabular}

*Values represent the mean \pm SE of three separate experiments. ${ }^{\ddagger} \mathrm{HDMEC}$ cells were fixed for 30 min using a solution of PBS containing $1 \%$ formaldehyde. ${ }^{8}$ Individual receptor contributions were calculated by subtracting the level of binding seen in the presence of both anti-ICAM-1 and antiCD36 mAbs from that seen in the presence of only one of the two mAbs. "Calculated by subtracting the level of binding seen in the presence of both anti-ICAM-1 and anti-CD36 mAbs from that seen when no mAbs are present.

III) and the second was to examine IE adhesion to known site densities of individual receptors (Fig. 5). In contrast to our observations on intact endothelium, synergy between ICAM-1 and CD36 was not observed when receptors were immobilized on plastic surfaces. Instead the two receptors appeared to make an approximately additive contribution to parasite binding.

Endothelial receptor immobilization abolishes synergy on $H D M E C$. The different results in these two systems implied important differences in the two model systems. These may include receptor conformation, accessibility, mobility, or posttranslational modification. To examine the importance of mobility we used two techniques to immobilize receptors within the HDMEC membrane: prior fixation of HDMEC with formalin, and determination of IE binding at $4^{\circ} \mathrm{C}$. Neither procedure destroyed IE binding to purified ICAM-1 or CD36 when presented on plastic, nor did they destroy recognition of receptor epitopes on HDMEC when examined using adhesion blocking mAbs (data not shown). However, both means of immobilizing receptors did alter IE adhesion to HDMEC (Table IV). At $37^{\circ} \mathrm{C}$, formalin fixation caused a decrease in cytoadherence, reducing the level of adhesion supported by either ICAM-1 or CD36 alone. In contrast, immobilizing membrane receptors by carrying out $\mathrm{IE}$ adherence at $4^{\circ} \mathrm{C}$ resulted in an increase in the level of adhesion supported by either ICAM-1 or CD36 alone. Both techniques dramatically reduced the extent to which ICAM-1 and CD36 synergized on TNF-activated HDMEC.

\section{Discussion}

We have studied the relative roles of two endothelial receptors, CD36 and ICAM-1, in the adherence of $P$. falciparum IEs to human microvascular endothelium under varying activation conditions. We have demonstrated that when coexpressed on endothelial cells, the two receptors act synergistically in mediating the adhesion of a number of different parasite clones, in a manner which appears to require membrane mobility.

Multiple receptor interactions are important for many adhesion-dependent processes, conferring specificity, delivering signals, and increasing the strength of adhesion. In the case of leukocyte adhesion, selectin-mediated rolling is followed by cellular activation through chemokines and possibly directly by selectin engagement. Leukocyte activation leads to conformational changes in integrins and the induction of high-affinity and high-avidity binding to immunoglobulin superfamily ligands. Binding may also be enhanced by soluble molecules able to act as bridges between interacting cells. This appears to be the case for the interaction of leukocytes with ICAM-1-expressing endothelium, where fibrinogen binds to a site in the first domain of ICAM-1 and interacts with the leukocyte to enhance $\beta 2$-integrin-dependent binding $(39,40)$. Another example is the requirement for phagocytic cells to possess both the vitronectin receptor, $\alpha \mathrm{v} \beta 3$, and CD36 to confer competence for the ingestion of apoptotic neutrophils in a process which requires a third (soluble) molecule, thrombospondin (41).

We speculated that multiple receptor interactions would play a role in the endothelial adherence of IEs, based on two observations. First, most clinical isolates are known to bind to more than one receptor and several lines of evidence indicate that this is also a property of individual cells rather than merely reflecting the presence of subpopulations within the culture or isolate. Second, the deduced primary amino acid sequence of the $P$. falciparum var gene family indicates that the PfEMP1 proteins contain multiple domains homologous to the adhesive domains of the Duffy antigen-binding protein from Plasmodium vivax and the erythrocyte-binding antigen of $P$. falciparum, EBA-175. Thus the Duffy binding domain-like domains within a PfEMP1 molecule are strong candidates as adhesive modules with other specificities, and the presence of multiple domains suggests there is selective advantage for a single molecule to be capable of binding more than one host receptor. Therefore, we have addressed the question of how CD36 and ICAM-1 interact in mediating the adhesion of IEs to endothelial cells.

We began by isolating and characterizing HDMEC. The presence of constitutive and inducible markers identifies these cells as endothelial (von Willebrand factor and CD31 expression, VCAM-1 and E-selectin induction by TNF). In previous studies, adhesion of two parasite lines to HDMEC under flow conditions was examined and a role for both ICAM-1 and CD36 was demonstrated. No effect of TNF activation was noted, but the presence of high levels of ICAM-1 on the cells before activation indicates differences either in the population of dermal endothelial cells isolated or in culture conditions.

Our data demonstrate that CD36 and ICAM-1 can synergize in mediating the adherence to human microvascular endothelium of IEs from multiple clones of parasite. They indicate that populations of infected cells exist which are only 
competent to adhere when both adhesion receptors are present. Although a formal possibility is that our observations can be explained by the presence of independent clonal populations with nonoverlapping adhesive capabilities, the inhibition of the activation-dependent, ICAM-1-dependent adhesion by anti-CD36 mAb would still indicate some form of "help" between such hypothetical populations. However, we have also seen synergy using a highly antigenically homogenous parasite line selected from the A4 clone by direct panning on a surface coated with a variant-specific mAb, BC6 (4). Indeed, levels of synergy with this parasite line are greater than those observed with the less antigenically homogeneous line A4 (data not shown). Thus, we conclude that synergy is a property of parasites expressing particular var genes and the degree of synergy seen is a function of the proportion of those clones in the whole parasite population. This finding is in keeping with our previous observations of the relationship between antigenic and phenotypic variation and the importance of subpopulations in determining the overall population phenotype $(35,42)$. Our data are important for two reasons. First, although we clearly show a major role for CD36 as a receptor, we also demonstrate that in the presence of CD36, the induction of ICAM-1 expression exerts a major influence on binding. This has implications for the adherence of IEs in vivo, since we have shown that both fatal and nonfatal malaria are accompanied by endothelial activation and increased ICAM-1 expression. Synergy could strongly influence the pattern of sequestration throughout the host, depending on the relative levels of CD36 and ICAM-1 in different vascular beds. Second, our data demonstrate important drawbacks to the study of adhesion to individual receptors in environments outside the cell membrane. The overall level of adhesion to endothelial cells may be much greater than that predicted by studying individual receptors; indeed for one clone no significant adhesion was detected to purified ICAM-1, yet synergy was demonstrated on intact HDMEC. This is of particular importance when trying to correlate the adhesion of infected cells to individual receptors with clinical syndromes, and the results of such studies, including our own (43), must now be interpreted with caution. This consideration has relevance beyond malaria, wherever attempts are made to correlate adhesion to a single receptor with behavior in a complex cell-based system.

The mechanism of receptor synergy remains to be elucidated. Our data suggest that the phenomenon depends on receptor mobility within the endothelial cell membrane. Synergy was almost completely abolished by formalin fixation or when binding was carried out at $4^{\circ} \mathrm{C}$. These interventions restrict the mobility of receptors within membranes but do not affect $\mathrm{mAb}$ epitopes nor IE binding to purified immobilized receptors. Furthermore, synergy could not be reproduced using unfixed purified immobilized receptors at $37^{\circ} \mathrm{C}$ at site densities equivalent to those found on HDMEC. These data are compatible with our earlier observations that adhesion of individual IEs that were micromanipulated into contact with endothelial cells showed a strength of association that increased with time, suggesting an "adhesion-strengthening" event. We speculate that this event primarily involves the recruitment of additional receptors to the area of cell-cell contact by lateral diffusion within the endothelial cell membrane. This process would be too slow to operate under flow conditions, which explains the very efficient behavior of ICAM-1 as a rolling receptor, but the relative ease with which cells adhering via ICAM-1 alone can be removed from experimental assays by over vigorous washing.

In conclusion, our observations in this and previous studies provide two ways by which ICAM-1, or other as yet unidentified accessory receptors, can greatly increase the efficiency of CD36-mediated adhesion; first by generating rolling adhesion under flow conditions and second by acting in synergy once the IE has come to rest. Further elucidation of these interactions will require real-time flow-based observations of adhesion to microvascular endothelium under carefully controlled activation conditions using parasite clones and isolates with well-defined adhesive capabilities.

\section{Acknowledgments}

We thank Drs. N. Hogg (ICRF Lincoln's Inn Field, London, UK), D. Haskard (Guy's Hospital, London, UK), J. Barnwell (New York University Medical Center, New York), and J. MacGregor (Faculty of Medicine Alex Carrel, Lyon, France) for their gifts of mAbs. We are also grateful to Dr. C. Ockenhouse (WRAIR, Washington, DC) for providing the various parasite lines, and to Robert Pinches for assistance with parasite culture and radiolabeling of antibodies. Finally, we acknowledge help provided by Nancy Polson (Becton Dickinson) in obtaining Falcon bacteriological plastic 96-well plates.

This work was supported by the Lister Institute of Preventive Medicine, the Wellcome Trust, and the Medical Research Council of Great Britain. Christopher McCormick received a Medical Research Council Studentship, David Roberts is a Wellcome Trust Senior Clinical Fellow, and Anthony Berendt is a Lister Institute Research Fellow.

\section{References}

1. MacPherson, G.G., M.J. Warrell, N.J. White, S. Looareesuwan, and D.A. Warrell. 1985. Human cerebral malaria. A quantitative ultrastructural analysis of parasitized erythrocyte sequestration. Am. J. Pathol. 119:385-401.

2. Pongponratn, E., M. Riganti, B. Punpoowong, and M. Aikawa. 1991. Microvascular sequestration of parasitized erythrocytes in human falciparum malaria: a pathological study. Am. J. Trop. Med. Hyg. 44:168-175.

3. Baruch, D.I., B.L. Pasloske, H.B. Singh, X. Bi, X.C. Ma, M. Feldman, T.F. Taraschi, and R.J. Howard. 1995. Cloning the P. falciparum gene encoding PfEMP1, a malarial variant antigen and adherence receptor on the surface of parasitized human erythrocytes. Cell. 82:77-87.

4. Smith, J.D., C.E. Chitnis, A.G. Craig, D.J. Roberts, D.E. Hudson-Taylor, D.S. Peterson, R. Pinches, C.I. Newbold, and L.H. Miller. 1995. Switches in expression of Plasmodium falciparum var genes correlate with changes in antigenic and cytoadherent phenotypes of infected erythrocytes. Cell. 82:101-110.

5. Su, X.-Z., V.M. Heatwole, S.P. Wertheimer, F. Guinet, J.A. Herrfeldt, D.S. Peterson, J.A. Ravetch, and T.E. Wellems. 1995. The large diverse gene family var encodes proteins involved in cytoadherence and antigenic variation of Plasmodium falciparum-infected erythrocytes. Cell. 82:89-100.

6. Roberts, D.D., J.A. Sherwood, S.L. Spitalnik, L.J. Panton, R.J. Howard, V.M. Dixit, W.A. Frazier, L.H. Miller, and V. Ginsburg. 1985. Thrombospondin binds falciparum malaria parasitized erythrocytes and may mediate cytoadherence. Nature. 318:64-66.

7. Barnwell, J.W., A.S. Asch, R.L. Nachman, M. Yamaya, M. Aikawa, and P. Ingravallo. 1989. A human 88-kD membrane glycoprotein (CD36) functions in vitro as a receptor for a cytoadherence ligand on Plasmodium falciparuminfected erythrocytes. J. Clin. Invest. 84:765-772.

8. Ockenhouse, C.F., N.N. Tandon, C. Magowan, G.A. Jamieson, and J.D. Chulay. 1989. Identification of a platelet membrane glycoprotein as a falciparum malaria sequestration receptor. Science. 243:1469-1471.

9. Oquendo, P., E. Hundt, J. Lawler, and B. Seed. 1989. CD36 directly mediates cytoadherence of Plasmodium falciparum parasitized erythrocytes. Cell. 58:95-101.

10. Berendt, A.R., D.L. Simmons, J. Tansey, C.I. Newbold, and K. Marsh. 1989. Intercellular adhesion molecule-1 is an endothelial cell adhesion receptor for Plasmodium falciparum. Nature. 341:57-59.

11. Ockenhouse, C.F., T. Tegoshi, Y. Maeno, C. Benjamin, M. Ho, K.E. Kan, Y. Thway, K. Win, M. Aikawa, and R.R. Lobb. 1992. Human vascular endothelial cell adhesion receptors for Plasmodium falciparum-infected erythrocytes: roles for endothelial leukocyte adhesion molecule 1 and vascular cell adhesion molecule 1. J. Exp. Med. 176:1183-1189.

12. Rogerson, S.J., S.C. Chaiyaroj, K. Ng, J.C. Reeder, and G.V. Brown. 
1995. Chondroitin sulfate A is a cell surface receptor for Plasmodium falciparum-infected erythrocytes. J. Exp. Med. 182:15-20.

13. Kuzu, I., R. Bicknell, A.L. Harris, M. Jones, K.C. Gatter, and D.Y. Mason. 1992. Heterogeneity of vascular endothelial cells with relevance to diagnosis of vascular tumours. J. Clin. Pathol. 45:143-148.

14. Ketis, N.V., J. Lawler, R.L Hoover, and M.J. Karnovsky. 1988. Effects of heat shock on the expression of thrombospondin by endothelial cells in culture. J. Cell Biol. 106:893-904.

15. Pober, J.S., M.A. Gimbrone, Jr., L.A. Lapierre, D.L. Mendrick, W. Fiers, R. Rothlein, and T.A. Springer. 1986. Overlapping patterns of activation of human endothelial cells by interleukin 1, tumor necrosis factor, and immune interferon. J. Immunol. 137:1893-1896.

16. Wellicome, S.M., M.H. Thornhill, C. Pitzalis, D.S. Thomas, J.S.S. Lanchbury, G.S. Panayi, and D.O. Haskard. 1990. A monoclonal antibody that detects a novel antigen on endothelial cells that is induced by tumor necrosis factor, IL-1, or lipopolysaccharide. J. Immunol. 144:2558-2565.

17. Turner, G.D.H., H. Morrison, M. Jones, T.M.E. Davis, S. Looareesuwan, I.D. Buley, K.C. Gatter, C.I. Newbold, S. Pukritayakamee, B. Nagachinta, et al. 1994. An immunohistochemical study of the pathology of fatal malaria. Evidence for widespread endothelial activation and a potential role for intercellular adhesion molecule-1 in cerebral sequestration. Am. J. Pathol. 145:10571069 .

18. Fried, M., and P.E. Duffy. 1996. Adherence of Plasmodium falciparum to chondroitin sulfate A in the human placenta. Science. 272:1502-1504.

19. Sherwood, J.A., D.D. Roberts, K. Marsh, E.B. Harvey, S.L. Spitalnik, L.H. Miller, and R.J. Howard. 1987. Thrombospondin binding by parasitized erythrocyte isolates in falciparum malaria. Am. J. Trop. Med. Hyg. 36:228-233.

20. Hasler, T., S.M. Handunnetti, J.C. Aguiar, S.M. van Schravendijk, B.M. Greenwood, G. Lallinger, P. Cegielski, and R.J. Howard. 1990. In vitro rosetting, cytoadherence, and microagglutination properties of Plasmodium falciparum-infected erythrocytes from Gambian and Tanzanian patients. Blood. 76: $1845-1852$

21. Ockenhouse, C.F., M. Ho, N.N. Tandon, G.A. Van Seventer, S. Shaw, N.J. White, G.A. Jamieson, J.D. Chulay, and H.K. Webster. 1991. Molecular basis of sequestration in severe and uncomplicated Plasmodium falciparum malaria: differential adhesion of infected erythrocytes to CD36 and ICAM-1. J. Infect. Dis. 164:163-169.

22. Marsh, K., V.M. Marsh, J. Brown, H.C. Whittle, and B.M. Greenwood. 1988. Plasmodium falciparum: the behavior of clinical isolates in an in vitro model of infected red blood cell sequestration. Exp. Parasitol. 65:202-208.

23. Lawrence, M.B., and T.A. Springer. 1991. Leukocytes roll on a selectin at physiologic flow rates: distinction from and prerequisite for adhesion through integrins. Cell. 65:859-873.

24. Cooke, B.M., A.R. Berendt, A.G. Craig, J. MacGregor, C.I. Newbold, and G.B. Nash. 1994. Rolling and stationary cytoadhesion of red blood cells parasitized by Plasmodium falciparum: separate roles for ICAM-1, CD36 and thrombospondin. Br. J. Haematol. 87:162-170.

25. Schmidt, J.A., I.J. Udeinya, J.H. Leech, R.J. Hay, M. Aikawa, J. Barnwell, I. Green, and L.H. Miller. 1982. Plasmodium falciparum malaria: an amelanotic melanoma cell line bears receptors for the knob ligand on infected erythrocytes. J. Clin. Invest. 70:379-386.

26. Barnwell, J.W. C.F. Ockenhouse, and D.M. Knowles. 1985. Monoclonal antibody OKM5 inhibits the in vitro binding of Plasmodium falciparum-infected erythrocytes to monocytes, endothelial, and C32 melanoma cells. J. Immunol. 135:3494-3497.

27. Udeinya, I.J., J.A. Schmidt, M. Aikawa, L.H. Miller, and I. Green. 1981.
Falciparum malaria infected erythrocytes specifically bind to cultured human endothelial cells. Science. 213:555-557.

28. Swerlick, R.A., K.H. Lee, T.M. Wick, and T.J. Lawley. 1992. Human dermal microvascular endothelial but not human umbilical vein endothelial cells express CD36 in vivo and in vitro. J. Immunol. 148:78-83.

29. Swerlick, R.A., E. Garcia-Gonzalez, Y. Kubota, Y.L. Xu, and T.J. Lawley. 1991. Studies of the modulation of MHC antigen and cell adhesion molecule expression on human dermal microvascular endothelial cells. J. Invest. Dermatol. 97:190-196.

30. Johnson, J.K., R.A. Swerlick, K.K. Grady, P. Millet, and T.M. Wick. 1993. Cytoadherence of Plasmodium falciparum-infected erythrocytes to microvascular endothelium is regulatable by cytokines and phorbol ester. J. Infect. Dis. 167:698-703.

31. Tandon, N.N., R.H. Lipsky, W.H. Burgess, and G.A. Jamieson. 1989. Isolation and characterization of platelet glycoprotein IV (CD36). J. Biol. Chem. 264:7570-7575.

32. Jaffe, E.A., R.L. Nachman, C.G. Becker, and C.R. Minick. 1973. Culture of human endothelial cells derived from umbilical veins. Identification by morphologic and immunologic criteria. J. Clin. Invest. 52:2745-2756.

33. Davison, P.M., K. Bensch, and M.A. Karasek. 1980. Isolation and growth of endothelial cells from the microvessels of the newborn human foreskin in cell culture. J. Invest. Dermatol. 75:316-321.

34. Marks, R.M., M. Czerniecki, and R. Penny. 1985. Human dermal microvascular endothelial cells: an improved method for tissue culture and a description of some singular properties in culture. In Vitro Cell. Dev. Biol. 21:627635

35. Imcke, E., Z. Ruszczak, A. Mayer da Silva, M. Detmar, and C.E. Orfanos. 1991. Cultivation of human dermal microvascular endothelial cells in vitro: immunocytochemical and ultrastructural characterization and effect of treatment with three synthetic retinoids. Arch. Dermatol. Res. 283:149-157.

36. Roberts, D.J., A.G. Craig, A.R. Berendt, R. Pinches, G. Nash, K. Marsh, and C.I. Newbold. 1992. Rapid switching to multiple antigenic and adhesive phenotypes in malaria. Nature. 357:689-692.

37. Trager, W., and J.B. Jensen. 1976. Human malaria parasites in continuous culture. Science. 193:673-675.

38. Fraker, P.J., and J.C.J. Spreck. 1978. Protein and cell membrane iodinations with a sparingly soluble chloroamide, 1,3,4,6-tetrachloro-3a,6a-diphrenylglycoluril. Biochem. Biophys. Res. Commun. 80:849-857.

39. Languino, L.R., J. Plescia, A. Duperray, A.A. Brian, E.F. Plow, J.E. Geltosky, and D.C. Altieri. 1993. Fibrinogen mediates leukocyte adhesion to vascular endothelium through an ICAM-1-dependent pathway. Cell. 73:14231434.

40. Duperray, A., L. Languino, J. Plescia, A. McDowell, N. Hogg, A. Craig, A.R. Berendt, and D.C. Altieri. 1997. Molecular identification of a novel fibrinogen binding site on the first domain of ICAM-1 regulating leukocyte-endothelium bridging. J. Biol. Chem. 272:435-441.

41. Savill, J., N. Hogg, Y. Ren, and C. Haslett. 1992. Thrombospondin cooperates with CD36 and the vitronectin receptor in macrophage recognition of neutrophils under apoptosis. J. Clin. Invest. 90:1513-1522.

42. Gardner, J.P., R.A. Pinches, D.J. Roberts, and C.I. Newbold. 1996. Variant antigens and endothelial receptor adhesion in Plasmodium falciparum. Proc. Natl. Acad. Sci. USA. 93:3503-3508.

43. Newbold, C.I., P. Warn, G. Black, A.R. Berendt, A. Craig, R. Snow, M. Msobo, N. Peshu, and K. Marsh. 1997. Receptor specific adhesion and clinical disease in Plasmodium falciparum malaria. Am. J. Trop. Med. Hyg. In press. 